\title{
Synthesis of the Control Algorithm for a Maneuver of Avoidance of Collision with the Terrain
}

\author{
E. A. Evdokimchik, obstwasser@mail.ru $\bowtie$, \\ MiG Co., Moscow, 125284, Russian Federation
}

Corresponding author: Evdokimchik E. A., Engineer of the 1st Category, MiG Co., Moscow, 125284, Russian Federation, e-mail: obstwasser@mail.ru

Received on February 26, 2016

Accepted on March 14, 2016

\begin{abstract}
A controlled flight into terrain remains a serious problem for the commercial and military aircraft. Necessity of monitoring the height and other parameters of movement during operations near the ground increases load on a pilot and diverts him from his specific tasks. So, the efficiency of the task implementation is reduced. It is difficult for a pilot to adequately estimate the degree of maneuverability and safety on a modern maneuverable aircraft. To improve the flight safety applies systems which warns the pilot of the ground proximity and performs an automatic collision avoidance maneuver. We have ground collision avoidance systems based on the trajectory prediction and calculation of the height lost during the automatic collision avoidance maneuver. The available dynamic characteristics of an aircraft should be taken into account for development of the control algorithms in such systems. The article deals with the synthesis of the control algorithms for performance of the automatic maneuvers intended to avoid collision with the ground in accordance with the current parameters of movement and maneuvering characteristics of the aircraft. Analysis was done of the influence of the parameters of the control algorithms in different initial conditions and different characteristics of g-load and roll angle control loops. The logic for selection of the direction of rotation to achieve the wings' level position in the shortest time was considered. The proposed algorithm is applied in the aircraft with control loops of g-load and roll angle.
\end{abstract}

Keywords: automatic maneuvers intended to avoid collision with the ground, synthesis of the control algorithm

For citation:

Evdokimchik E. A. Synthesis of the Control Algorithm for a Maneuver of Avoidance of a Collision with the Terrain, Mekhatronika, Avtomatizatsiya, Upravlenie, 2016, vol. 17, no. 7, pp. 492-498.

DOI: $10.17587 /$ mau.17.492-498

\section{References}

1. Patent 4058710 USA, Process for preventing undesired contact with land or water by low-flying aircraft, Altmann H., 15.11.1977, available at: http:// www.google.com/ patents/US4058710 (date of access 07.12.2015).

2. Patent 4924401 USA, Aircraft ground collision avoidance and autorecovery systems device, Bice G., Skoog M., Howard J., 08.05.1990, available at: https:// www.google.com.ar/patents/US4924401 (date of access 07.12.2015).
3. Swihart D. Automatic Ground Collision Avoidance System (Auto GCAS), ICS 09, 13th World Scientific and Engineering Academy and Society International Conference on Systems, Rodos Island, Greece, 2009, available at: http://www.wseas.us/e-library/conferences/2009/ rodos/SYSTEMS/SYSTEMS63.pdf (date of access 19.12.2015).

4. Evdokimchik E. A. Sistema avtomaticheskogo uvoda ot opasnoj vysoty s prognozirovaniem vysoty zavershenija manevra (Automatic removal system from a dangerous height prediction altitude maneuver is complete), Trudy MAI, 2015, no. 80, available at: http:// www.mai.ru/upload/iblock/56b/56b53d1 e6edc3dcc106f3b10a1d5 ec83.pdf (date of access 19.02.2016).

5. Lebedev A. A., Chernobrovkin L. C. Dinamika poleta bespilotnykh letatel'nikh apparatov (Flight dynamics of pilotless flight vehicles), Moscow, Mashinostroenie, 1973, 616 p. (in Russian).

6. Bjushgens G. S., Studnev R. V. Dinamika samoleta. Prostranstvennoe dvizhenie (The dynamics of the aircraft. Spatial movement), Moscow, Mashinostroenie, 1983, 320 p. (in Russian).

л. С. Раткин, канд. техн. наук, зам. генерального директора,

ООО "АРГМ", г. Москва

\section{Сравнительный анализ промышленных и экологических беспилотных комплексов воздушного, наземного, подземного, надводного и подводного типов с защитой каналов связи методами компьютерной стеганографии}

В соответствии с предлагаемой классификацией кратко характеризуются современные разработки в области беспилотных многоцелевых комплексов. Кратко рассмотрены промышленные и экологические беспилонтных многоцелевых комплексов воздушного, наземного, подземного, надводного и подводного типов с защитой каналов связи методами компьютерной стеганографии.

Ключевые слова: беспилотные многоцелевые комплексы, промышленный мониторинг, экологический мониторинг, стеганография, автоматизация 
Среди множества направлений развития современных беспилотных многоцелевых комплексов (БМК) наиболее инвестиционно-привлекательными для производственных предприятий являются применения, связанные, в частности, с промышленной безопасностью и экологическим мониторингом. Инвестиционные проекты, связанные с разработкой промышленных и экологических БМК, часто реализуются по заданиям конкретных компаний с участием их собственных средств и государственной поддержки как гарантии возврата кредита при реализации крупной госпрограммы. Как правило, такие проекты быстро окупаемы (срок окупаемости часто не превышает 12 месяцев), а получаемое разработчиком по заказу генерального подрядчика решение становится основой для создания нового поколения БМК, которое можно использовать при создании изделия для других заказчиков. Другой отличительной особенностью промышленных и экологических БМК является их невысокая стоимость (по сравнению с БМК двойного назначения или военного применения), предполагающая их серийное производство с последующим гарантийным и постгарантийным техническим обслуживанием. Третья особенность БМК связана с их уязвимостью: блокировка хакером основных систем управления и перехват контроля над БМК может привести к техногенной катастрофе или террористическому акту. Например, за рубежом с 2013 г. квантовые компьютеры применяются для взлома криптографических систем защиты данных: скорость их работы на основе анализа результатов 50 базовых тестов на три порядка превышает скорость современных вычислительных систем. Это накладывает важное дополнительное условие по оснащению БМК системами защиты каналов связи методами, отличными от криптографических, например, стеганографическими.

Компьютерная стеганография - перспективное направление, принципиально отличающееся от криптографии. Если в криптографии происходит передача сообщения, зашифрованного ключом, то в стеганографии скрывается сам факт передачи сообщения! В стеганографии между приемником и передатчиком формируется поток сообщений, в каждом из которых может присутствовать лишь часть сообщения, которое также может быть зашифровано. Поскольку шифрование сообщений выборочно, а местонахождение частей скрываемого сообщения между приемником и передатчиком неизвестно, задача перехвата управления БМК многократно усложняется. Хакеру, пытающемуся перехватить контроль над БМК, видна лишь последовательность сообщений, в каждом из которых, как в контейнере, присутствует шифруемая или нешифруемая инструкция (или ее часть) по управлению БМК. Извлечение из информационных контейнеров (называемых стеганографическим) и восстановление последовательности управляющих инструкций возможно только на БМК, а перехватчик-хакер получает постоянно растущий объем данных, из которого выборочно (алгоритм извлечения ему неизвестен) по определенным адресам (также неизвестным) происходит скрытая передача информации. В такой ситуации при постоянно растущем информационном объеме задача выборочного извлечения шифруемых по уникальным ключам частей управляющих инструкций для БМК многократно усложняется, что повышает уровень защиты каналов связи БМК.

По сравнению с криптографией компьютерная стеганография предоставляет дополнительные преимущества в защите данных, так как шифроваться может каждая часть сообщения со своим уникальным ключом, который, как и другое сообщение, может также передаваться, но уже в другом контейнере (группе контейнеров). Последовательность стеганографических контейнеров (стегоконтейнеров), в которых выборочно размещается часть управляющих инструкций для БМК, сочетается с информационными системами криптографической защиты данных, что снижает стоимость интеграции стеганографических и криптографических систем защиты каналов связи БМК, повышает уровень их информационной защиты от перехвата управления по каналам связи и увеличивает надежность применяемых программно-технических решений. Кратко рассмотрим промышленные и экологические БМК воздушного, наземного, подземного, надводного и подводного типов с защитой каналов связи методами компьютерной стеганографии.

\section{Авиационные БМК}

БМК вертолетного типа. В рамках программы по созданию беспилотного комплекса для решения сложных задач в опасных для человека зонах Московским вертолетным заводом имени М. Л. Миля [2] разработан беспилотный вертолет Ми-34БП (рис. 1, см. третью сторону обложки), предназначенный для контроля безопасности движений на автодорогах, ледовой разведки, обеспечения спасательных операций, теле-, фото- и киносъемки, круглосуточного обзора земной поверхности с передачей на Землю телевизионного и тепловизионного изображения конкретных объектов или местности, мониторинга нефтегазопроводов и АЭС, экомониторинга, выполнения функций сельхозавиации, трансляции и ретрансляции информации. В состав базового комплекса входят системы управления вертолетом, траекторного управления и посадки, наземная часть комплекса - станция управления (СУ), автопилот, радиолинии связи Ми-34БП-Су, а также стационарное или съемное целевое оборудование в зависимости от вариантов применения, в том числе для интеграции в информационную систему мониторинга и контроля за состоянием воздушных судов [3]. При массе пустого вертолета в базовой комплектации 900 кг целевая нагрузка составляет не более 300 кг. Максимальная взлетная масса составляет 1450 кг, мощность - 500 л. с. Практический потолок при полетной массе 1,350 т 3,5 км, 1,28 т и менее - 4 км. Диаметр несущего винта 10 м с двигателем ГТД АИ-450 (Arrius-2) обеспечивает максимальную скорость полета - 
225 км/ч, крейсерскую - 190 км/ч. При сроке вертолета не менее 30 лет средний межремонтный ресурс составляет 1200...1500 ч. Дальность полета с полной заправкой - 520 км. Возможно применение стеганографии для защиты каналов связи.

БПЛА вертолетного типа производства фирмы "Schiebel" [4] с дублирующими друг друга инерционной и географической информационной системами навигации (INS и GPS) применяется для топографической съемки и точного мониторинга, охраны границ, дневного/ночного патрулирования, обеспечения безопасности на море, точечного и масштабного наблюдения и мониторинга состояния нефтегазопроводов (рис. 2, см. третью сторону обложки). Передача данных и видеоизображения обеспечивается в сжатом виде (до 4 параллельных видеоканалов) с дальностью передачи 80/180 км (43/97 нм). Применяемая для увеличения радиуса полета крейсерская скррость составляет 55 узлов (102 км/ч) при максимальной скорости 120 узлов $(220 \mathrm{kм} /$ ч). При массе без топлива и аппаратуры 100 кг максимальная взлетная масса составляет 200 кг, загрузка -50 кг и время полета -6 ч с загрузкой 25 кг. Диаметр главного винта $-3,4$ м. В системе управления допустимо применение компьютерной стеганографии.

Вертолетные БMK ZALA 421-02 (рис. 3, см. третью сторону обложки) и ZALA 421-05Н (рис. 4, см. третью сторону обложки) производства ижевской фирмы "Беспилотные системы" [5] предназначены для выполнения технологических операций по биологической, инженерной, химической и радиационной разведке, а также контроля технического состояния нефтегазовых и химических магистралей с применением компьютерной стеганографии. Тактико-технические характеристики (ТTX) перечисленных БМК представлены в таблице.

Сопоставляя характеристики в таблице, необходимо отметить, что в отличие от многочисленного класса самолетных БМК в БМК других типов чис-

\begin{tabular}{|c|c|c|c|c|}
\hline \multirow[b]{2}{*}{ Параметры } & \multicolumn{4}{|c|}{ ТТХ БМК/Модель } \\
\hline & $\begin{array}{c}\text { ZALA } \\
421-05 \mathrm{H}\end{array}$ & $\begin{array}{l}\text { ZALA } \\
421-02\end{array}$ & Schiebel & $\begin{array}{c}\text { Ми- } \\
\text { 34БП-Су }\end{array}$ \\
\hline Радиус действия, км & До 40 & До 50 & $\begin{array}{l}\text { Г } \\
\mathrm{bx}\end{array}$ & $\begin{array}{c}\text { Нет } \\
\text { данных }\end{array}$ \\
\hline $\begin{array}{l}\text { Продолжительность } \\
\text { полета, мин }\end{array}$ & До 180 & До 360 & & До 170 \\
\hline $\begin{array}{l}\text { Максимальная ско- } \\
\text { рость, км/ч }\end{array}$ & 80 & 90 & 220 & 225 \\
\hline $\begin{array}{l}\text { Максимальная вы- } \\
\text { сота полета, км }\end{array}$ & 2 & 3 & $\begin{array}{c}\text { Нет } \\
\text { данных }\end{array}$ & $3,5-4$ \\
\hline Ширина БМК, см & 40 & 67 & 1040 & $\begin{array}{c}\text { Нет } \\
\text { данных }\end{array}$ \\
\hline $\begin{array}{l}\text { Длина } \\
\text { БМК, см }\end{array}$ & 157 & 264 & 311 & $\begin{array}{c}\text { Нет } \\
\text { данных }\end{array}$ \\
\hline $\begin{array}{l}\text { Высота } \\
\text { БМК, сN }\end{array}$ & 67 & 94 & 1249 & $\begin{array}{c}\text { Нет } \\
\text { данных }\end{array}$ \\
\hline $\begin{array}{l}\text { Диаметр основного } \\
\text { ротора, м }\end{array}$ & 1,77 & 3,064 & $\begin{array}{c}\text { Нет } \\
\text { данных }\end{array}$ & $\begin{array}{c}\text { Нет } \\
\text { данных }\end{array}$ \\
\hline $\begin{array}{l}\text { Масса полезной } \\
\text { нагрузки, кг }\end{array}$ & До 3,5 & До 40 & До 60 & 300 \\
\hline Взлет/посадка & $\begin{array}{c}\text { Вер- } \\
\text { тикально }\end{array}$ & $\begin{array}{c}\text { Вер- } \\
\text { тикально }\end{array}$ & $\begin{array}{c}\text { Вер- } \\
\text { тикально }\end{array}$ & $\begin{array}{c}\text { Вер- } \\
\text { тикально }\end{array}$ \\
\hline
\end{tabular}

ло моделей значительно меньше, и нередко сравнение модельного ряда затруднительно по причине отсутствия данных о некоторых характеристиках ряда моделей. Существующая подклассификация БМК внутри каждого вида по ключевым ТТХ (массе дальности полета и т. д.) предполагает сопоставление преимушеств и недостатков каждой модели только внутри каждого подкласса. При этом сравнение даже двух моделей из разных подклассов нецелесообразно и дезориентирует покупателя, поскольку они нередко имеют принципиально различные цели и задачи и, соответственно, системы обеспечения - функциональное оборудование и аппаратные комплексы. Например, в приведенной таблице при сравнении по массе полезной нагрузки модели значения различаются почти в 100 раз, так как в таблице собраны данные о моделях БМК трех разных классов. Поэтому в настоящей публикации данные о БМК других типов не приводятся в табличном формате, а распределены по тексту.

БМК аэростатного типа. Создаваемые технические решения на платформе аэростата отличаются от самолетных и вертолетных БМК более низкими ТТХ и, следовательно, финансово-экономическими показателями соответствующих проектов на их создание и, вместе с тем, значительным упрощением в эксплуатации. Производимые американской фирмой "Raytheon" (старт-ап Массачусетского технологического института) [6] аэростаты обладают грузоподъемностью 68 кг полезной нагрузки на высоту до 300 м и передают данные на расстояние до 12 км в течение пяти суток дежурства. Управление аэростатом с установленным на борту лазерным и ИК оборудованием с мобильного наземного пункта осуществляется экипажем из трех человек [7].

БМК на базе аэростата ИРКУТ-1А производства корпорации "ИРКУТ" [8] обеспечивают непрерывный мониторинг районов наблюдения, в частности, нефтегазопроводов или нефтегазохранилищ. На расстоянии до 5 Км по радиоканалу ТВ и ИК изображения передаются на наземный пункт управления с одновременным приемом и отображением информации от четырех аэростатных систем. В отличие от заправляемых топливом БМК самолетного и вертолетного типа максимальная продолжительность наблюдения с БМК аэростатного типа не ограничена, а в стандартный комплект входит стабилизированная ТВ/тепловизионная оптико-электронная система. Допустимо применение компьютерной стеганографии для защиты телекоммуникационных каналов.

БМК на технической платформе привязного аэростата "ПУМА" длиной 60,7 м, высотой 35,8 м и объемом $11809 \mathrm{~m}^{3}$ при объеме газа (гелия) $8600 \mathrm{M}^{3}$, производимый RosAeroSystems [9], применяется для экомониторинга, патрулирования участков нефтегазопроводов, обнаружения потенциально опасных для путепроводов низколетящих целей, телекоммуникации и охраны спецобъектов (рис. 5 , см. третью сторону обложки). Осуществляя наблюдение в течение 25 дней на высотах от 2 до 5 км при скорости ветра $35 . .46$ м/с, БМК способен нести на борту по- 
лезную нагрузку, гораздо бо́льшую, чем современные самолетные БМК аналогичного класса, - до 2,25 т. Автоматическая стеганографически защищенная система поддержания давления и радиоканальная коммутация с электропитанием по тросукабелю позволяет запитывать бортовые силовые установки мощностью до 32,5 кВт и подъемно-спускаемый комплекс скоростью от 100 до 180 м/мин.

\section{Сухопутные БМК}

Наземные БМК. Поскольку основные объекты нефтегазовой инфраструктуры имеют, как правило, наземное и подземное залегание, по-прежнему ключевыми техническими проблемами для наземных БМК, принципиально отличающими сухопутные "беспилотники" от воздушных и водных БМК, являются выбор шасси и оптимизация систем управления движением. К числу сухопутных, в частности, относятся система мониторинга Kinesys производства фирмы "SEW Eurodrive". БMK перемещается по монорельсу, развивая скорость до $80 \mathrm{KM} / 4$ с 50 КГ полезной нагрузки, и фиксирует подозрительные объекты с помощью лазерного дальномера и непрерывной видеосъемки. Отметим, что если прокладка рельса при движении вдоль путепровода предполагает пересечение водной преграды, то перемещение по трассе происходит с помощью не только основного (в том числе колес или гусениц), но и вспомогательного механизма (в частности, винта). БМК на гусеничном шасси "Negotiator" производства фирмы "iRobot" [10], основанной в 1990 г. при Массачусетском технологическом институте, также предназначен для решения задач мониторинга состояния объектов и обеспечения их безопасности: малая скорость машины $(5 \mathrm{kM} / 4)$ и ее малая масса $(3,8$ кг) упрощают ее интеграцию в инфраструктуру транспортных продуктопроводов.

Смешанной схемой питания "обычное топливо электроэнергия", способствующей значительному увеличению продолжительности автономной работы БМК при приемлемой цене, обладает наземный робот-гибрид LandShark производства фирмы "Black-I Robotics". Базовая комплектация с электропитанием обеспечивает движение БМК со скоростью $8 \mathrm{kM} / 4$ в течение 8 ч, а при интеграции в схему топливного модуля длительность непрерывной работы без подзарядки возрастает втрое - до одних суток. В предназначенном для патрулирования спецобъектов и мониторинга состояния технических объектов БМК используется механизм автоматического переключения двигателя на электропотребление. Для мониторинга состояния технических объектов при перемещении по холмистой местности и ровным участкам со скоростью до $30 \mathrm{KM} / ч$ фирмой "QuinetiQ" разработан модульный наземный робот Dragon Runner массой 7 кг [3], совместимый с технологиями защиты каналов связи методами компьютерной стеганографии.

В классе наземных БМК отечественного производства можно выделить разработанные в МГТУ им. Н. Э. Баумана [11] мобильные робототехнические комплексы (МРК) разведки и пожаротушения (РП), предназначенные для проведения визуальной и приборной разведки при аварийно-восстановительных и спасательных работах, в частности, на нефтегазопроводах и трубопроводных системах, а также для ликвидации очагов возгораний на спецобъектах, в том числе энергетической сферы. Комплекс оснащен датчиками температуры и газоанализаторами, ИК и телевизионной камерами. Помимо базовой в качестве дополнительной комплектации в состав МРК-РП могут включаться стегозащищенный комплекс средств пожаротушения и аварийно-спасательного инструмента, комплект средств охлаждения и тепловой защиты и тепловизор. При скорости передвижения до 1 м/с зона действия в условиях среднепересеченной местности составляет не менее 1 км при управлении по радиоканалу и не менее 200 м - по кабельной линии. Длительность непрерывной работы - не менее 3 ч с номинальной грузоподъемностью 30 кг и максимальной - 50 кг. Габаритные размеры МРК: $1300 / 950 \times 650 \times 800 \mathrm{мм}$, масса - не более $200 \mathrm{кг}$.

Созданный также в МГТУ им. Н. Э. Баумана [11] подвижный робототехнический комплекс для ликвидации последствий техногенных аварий предполагает использование в условиях химического заражения, разливов нефти и в других случаях (например, при работе в зонах с высоким уровнем радиации) проведение визуальной разведки и поиск образцов и проб для их транспортировки к местам хранения и проведения исследований. В состав дистанционно-управляемого робототехнического электромеханического комплекса входят два мобильных робота типа МРК-46, оснащенных фронтальным погрузчиком и пятистепенным манипулятором, бортовые системы энергообеспечения и управления, пост дистанционного управления и телевизионная система, аппаратура обеспечения бесперебойной работы канала связи и дополнительное оборудование. Грузоподъемность манипулятора/фронтального погрузчика составляет 100/130 кг, наибольший радиус действия по радиоканалу - 3 км.

Изготавливаемая на ОАО "КЭМЗ" совместная разработка МГТУ им. Н. Э. Баумана и ОАО "СПБ ПА" - многофункциональный робототехнический комплекс легкого класса "Варан" - также относится к классу сухопутных БМК, нацеленных, в частности, на антитеррористическую защиту нефтегазопроводов и промышленных трубопроводных систем. Для визуальной разведки, поиска и первичного диагностирования подозрительных предметов применяется специализированное теле- и навесное оборудование. Разработанный БМК является высокоманевренным гусеничным транспортным средством с большим диапазоном регулирования и инструментами высокоточного позиционирования БМК на местности, перерасчета координат и траектории движения с помощью встроенных компьютерных стегосистем. 
Подземные БМК. БМК-спелеологи не так часто применяются в нефтегазовой отрасли в силу специфики технологий прокладки путепроводных систем. Тем не менее, иногда при прокладке и эксплуатации нефтегазопроводов возникает необходимость анализа глубины залегания путепроводов, распределения нагрузки на грунт и проникновения в их труднодоступные участки. В связи с этим наибольший интерес представляют работы по проекту Chemical Robots военного агентства передовых исследований США DARPA. Предлагаемая корпорацией iRobot [10] концептуальная модель "мягких" роботов (МР) предполагает создание мобильных устройств, способных пробираться в отверстия, меньшие, чем диаметр самого робота. Возможно использование МР при технологических и экологических катастрофах для поиска и спасения людей, например в мегаполисах, и для сбора, систематизации и стеганографической защиты информации о состоянии технических коммуникаций и систем. К классу МР также относится способный к перемещению в трубах и по камням робот-змея OmniTread диаметром 7 см с "подвижной кожей" [3].

Среди российских аналогов МР можно отметить разработанный в ГНЦ РФ "Центральный научноисследовательский и опытно-конструкторский институт робототехники и технической кибернетики" [12] многофункциональный мобильный робот (ММР) "Змеелок-2" (рис. 6, см. третью сторону обложки), предназначенный для перемещения по поверхностям со сложным рельефом, мониторинга технического состояния путепроводных систем и манипулирования в труднодоступных местах объектами, как сопоставимыми, так и превосходящими ММР по массе. Благодаря длительному изучению особенностей функционирования отечественных и зарубежных мультимодульных систем (ММС) и отработке комплекса алгоритмов и программ для согласованного (синхронного) управления компонентами МMC в состав базовой модели вошли пятнадцать последовательно соединенных унифицированных автономных модулей (УАМ) с тридцатью степенями свободы. Коммутация ПЭВМ с ММС осуществляется через установленный в хвостовом УАМ приемопередатчик Bluetooth, в частности, управляющий работой лазерной подсветки и мини-телекамеры в головном модуле ММС. При общей массе 3,6 кг диаметр УАМ составляет $8 \mathrm{~cm}$, длина ММС - 1,05 м. Для базовой модели питания в 6 В хватает на 1 ч автономной работы в супервизорном режиме управления, позволяя достигать максимального момента по оси тангажа 16,5 кг/см, по оси курса 5,5 кг/см. Допустима стегозащита каналов связи.

\section{Водные БМК}

Среди новых разработок БМК водного типа можно отметить пятиметровый беспилотный катер производства ижевской фирмы "Беспилотные системы" [5] с массой полезной нагрузки до 250 кг и скоростью до 150 км/ч, применяемый в том числе

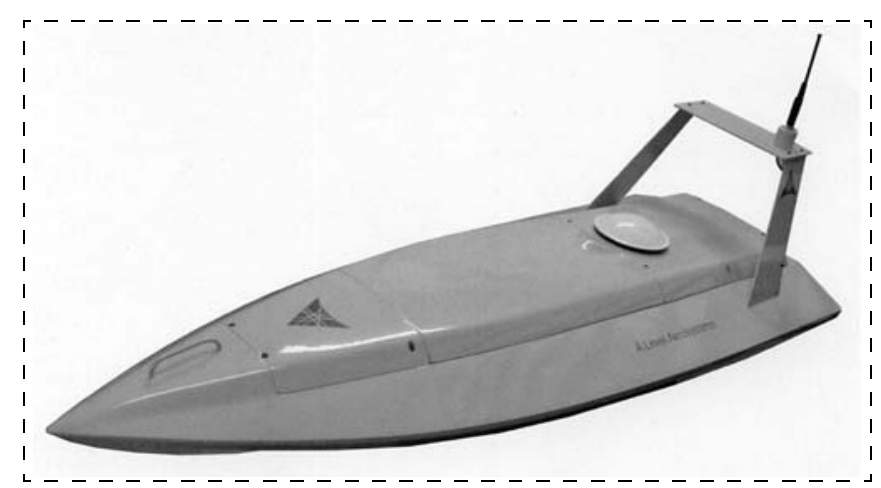

Рис. 7

для охраны береговых объектов нефтегазовой сферы. Имеющиеся в комплекте оборудования два БПЛА с автоматическим стартом могут использоваться для патрулирования подводных трубопроводных систем (рис. 7) со стегозащитой.

Проектируемые ФГУП "ЦНИИ "Гидроприбор" беспилотные малогабаритные телеуправляемые подводные аппараты применяются для проведения обследований и технических работ в свободной воде и освоения пространств Мирового океана. На роботизированной платформе оборудование БМК массой до 90 кг погружается на глубину до 250 м, обеспечивая поиск, добычу, переработку и трубопроводную транспортировку нефти и газа. Наиболее известные аналоги изделия по проекту - изделия серии "МТПА-РАПАН", среди зарубежных продукция шведской фирмы "SEA-EAGLE". Coгласно оценкам экспертов, потребности российских нефтегазовых предприятий в аппаратах составляют от 20...30 штук/год. Имеется стегоканал связи.

Также во ФГУП "ЦНИИ "Гидроприбор" разрабатывается беспилотный малогабаритный телеуправляемый подводный аппарат для проведения технических осмотров, обследовательских работ во внутренних полостях подводных объектов, в том числе трубопроводного транспорта. Отметим, БМК ФГУП дополняют друг друга (первый предназначен для работы в свободной воде, второй - в полостях объектов), поэтому различны применяемые телекоммуникационные технологии для осуществления связи беспилотных систем с сетью базовых приемопередающих станций и комплекты оборудования, входящие в состав аппаратов. Продукция оснащена ТВ камерами, гидролокатором и системой сбора данных в автоматическом режиме с записью информации на встроенный носитель при погружении на глубину до 300 м. Аппараты оснащены современным телекоммуникационным оборудованием во взрывозащищенном исполнении с дублированием блоков особо важных систем и блокированием опасных действий (например, при маневре с возможностью столкновения). Предусмотрен канал связи для стеганографической защиты управления.

Самоходный роботизированный беспилотный подводный аппарат размером 1,2 × 1,6 × 0,6 м массой 400 кг, состоящий из двигательного комплекса, гидравлической насосной станции, систем электро- 
питания, управления движением со стегозащитой контроля магнитного курса и гидроакустических маяков, ТВ системы, гидролокаторов секторного обзора, датчиков угловых перемещений и глубины, разработанный ЦНИИ "Гидроприбор", позволяет погружаться на глубину до 600 м с маршевой скоростью хода до 3 узлов и лаговой и вертикальной скоростью хода до 1,5 узлов.

Вообще, для подводных БМК характерно использование как различных сменных типов шасси, так и стартовых платформ. Например, подводный колесный робот LBV 150SE производства "SeeBotix" применяется для обследования подводных областей причалов и нефтеналивных терминалов и днищ танкеров. Записываемая на жесткий диск сонарная и видеоинформация доступна оператору в реальном времени. Устанавливаемая на БМК система формирования и анализа панорамных изображений производства фирмы "Augusta Systems" предназначена для охраны портов и нефтеналивных терминалов с размещением модулей слежения на подводных БМК и стационарных объектах. Во время саммита G8 в японской столице для охраны близлежащей береговой зоны и области вокруг АЭС Tomari применялся сонарный комплекс SeaBat производства корпорации ТОУО со стегозащитой.

В настоящее время ведутся разработки БМК подводного старта и воздушного или подводного перемещения. В частности, БМК Volans производства "ЕМТ" (Германия) запускаются с подводных аппаратов (ПА) и/или катапультируются с перископа подводной лодки и совершают часовой полет со скоростью 45...90 км/ч [7].

\section{Выводы}

1. Особенностью современного рынка многоцелевых комплексов по-прежнему является неустойчивость и неполнота терминологии ${ }^{1}$ и современной системы классификации. Следствием этого является не только отсутствие регулирующей деятельность БМК в РФ внутренне непротиворечивой нормативно-правовой базы и единой технологической платформы, препятствующее интеграции всего комплекса водных, сухопутных и воздушных БМК, но и несоответствие стандартов передачи данных, в том числе стеганографических: данная проблема приобретает угрожающие масштабы в связи с экспоненциальным характером роста числа разработок БМК.

2. До сих пор разработчиками не решен вопрос об однозначном использовании в БМК открытого или закрытого программного кода, поскольку от-

\footnotetext{
${ }^{1}$ Например, термин "многоцелевые" в аббревиатуре БМК может рассматриваться как "выбирающий и поддерживающий несколько целей - объектов наблюдения (т. е. более одного)", и вместе с тем как "мультифункциональный". Если в первом случае предполагается наличие специализированного целевого оборудования, то во втором возможно использование универсальных многофункциональных систем.
}

крытый код упрощает интеграцию разнородных технических решений и систем, соответственно снижая защиту систем БМК, а закрытый код повышает защиту программного обеспечения (ПО) БМК, одновременно усложняя интеграцию. Поэтому нередко процедура согласования окончательного варианта ПО для БМК тормозит время выхода новой продукции на рынок БМК, снижая эффективность разработки и прибыль от ее реализации.

3. Поскольку ряд продуктовых линеек БМК является многофункциональным, т. е. применимым, например, не только для нефтегазового комплекса, но и для патрулирования ядерных объектов, защиты территории, экологического мониторинга и т. д., в ближайшие годы планируется переход на новый интерфейс с заменой джойстиков и рулей на устройства управления нового поколения - трекболы и сенсорные экраны с системой выпадающих меню. Различные элементы интегрированного механизма управления БМК Advanced Cockpit в настоящее время отрабатываются в различных компьютерных играх и симуляторах и уже в следующем десятилетии станут доступны операторам БМК [13, 14].

Для согласованного управления группами беспилотных аппаратов [15] применима авторская технология компьютерной стеганографии, защищенная патентом на изобретение [16]. Применение компьютерной стеганографии в квадрокоптеpax (поликоптерах) и внутритрубных снарядах будет рассмотрено в следующей публикации.

\section{Список литературы}

1. Раткин Л. С. Сравнительный анализ беспилотных летательных аппаратов самолетного типа, применяемых для решения задач автоматизированного промышленного и экологического мониторинга состояний объектов // Мехатроника, автоматизация, управление. С. 58-62.

2. Официальный сайт холдинга "Вертолеты России". URL: www.mi-helicopter.ru.

3. Ратникова Н. А. Теоретические основы, аппаратные средства и программно-математическое обеспечение информационной системы мониторинга и контроля по состоянию воздушных судов. Дисс. ... на соискание ученой степени д.т.н. М., 2005.

4. Официальный сайт концерна "Schiebel". URL: www.schiebel.net.

5. Официальный сайт группы компаний ZALA AERO (г. Ижевск). URL: www.zala.aero.

6. История компании Raytheon. URL: http://www.raytheon.com/ ourcompany/history/.

7. Военные известия // PC WEEK/RE. 2016. № 1-5. C. 6.

8. Официальный сайт Корпорации "ИРКУТ" - www.irkut.com.

9. Официальный сайт RosAeroSystems - http://www.rosaerosystems.ru/

10. История компании iRobot. URL: http://www.irobot.com/ About-iRobot/Company-Information/History.aspx.

11. Официальный сайт МГТУ им. Н. Э. Баумана. URL: www.bmstu.ru.

12. Официальный сайт ГНЦ РФ "Центральный научно-исследовательский и опытно-конструкторский институт робототехники и технической кибернетики". URL: www.rtc.ru.

13. Шилов А. Е. Комплексный подход к созданию интегрированных глобальных навигационных спутниковых систем. Дисс. ... на соискание ученой степени к. т. н. М., 2007.

14. Мирзоян Л. А. Нейросетевая система планирования полета группы беспилотных летательных аппаратов. Дисс. ... на соискание ученой степени к. т. н. М., 2007.

15. Гайдук А. Р. Управление группой беспилотных летательных аппаратов с ограничением на управление и переменные состояния // Мехатроника, автоматизация, управление. С. 52-57.

16. Раткин Л. С. Патент на изобретение № 2322693. 


\title{
The Comparative Analyses for Industrial and Ecological Unmanned Complexes of Air, Land-On, Underground, Marine and Submarine with the Protection of Communication Channels Based on Methods of Computer Steganography
}

\author{
L. S. Rathkeen, rathkeen@bk.ru, ARGM LLC, Moscow, 119049, Russian Federation,
}

Corresponding author: Rathkeen Leonid S., Ph. D., ARGM LLC, Moscow, 119049, Russian Federation, e-mail: maybe78@gmail.com

Received on February 29, 2016 Accepted on March 20, 2016

The significant excess of demand over supply initiates the speed increasing of world market of unmanned multi-purposes complexes (MPC) last years. Except space unmanned systems and unmanned flying systems of aircraft type [1], also exists helicopter and balloon (zeppelin) aviation MPC, land-on and underground MPC, also marine and submarine MPC. According with the proposed classification shortly define and determine the modern MPC applications. The article is devoted to the helicopter, balloon (zeppelin), land-on and underground, marine and submarine MPC, designed by Russian and foreign scientific and industrial organizations and enterprises, including Moscow Mile helicopter plant, "Schiebel", "Unmanned systems", "Raytheon", "IRKUT", "RosAeroSystems", "SEW Eurodrive", "iRobot", "Black-I Robotics", "QuinetiQ", "KEMZ", "SPB PA" companies, "Central scientific researching and experience construction institute of robot-technique and technical cybernetics", "Central scientific research institute "Hydrodevice"'", "SEA-EAGLE", "SeeBotix", "Augusta Systems", "TOYO", "EMT", Bauman State University, Massachusetts technological institute, Harvard university and DARPA. This MPC may be used in different spheres, such as oil and gas monitoring, fire-protection systems, industrial safety, ecological equipment, bogy guard and other civil applications. The comparing of air, land-on, underground, marine and submarine MPC by financial and economical parameters supports the realization of regional investment projects. Much attention is paid for industrial and ecological monitoring with protection of communication channels based on computer steganographic technologies, which are protected by author's Russian patent for invention.

Keywords: multi-purposes complexes $(M P C)$, air MPC, unmanned aviation, land-on MPC, underground MPC, marine MPC, submarine MPC, industrial monitoring, ecological monitoring, data protection, communication channels, computer steganographic technologies systems, automatization

For citation:

Rathkeen L. S. The Comparative Analyses for Industrial and Ecological Unmanned Complexes of Air, Land-On, Underground, Marine and Submarine with the Protection of Communication Channels Based on Methods of Computer Steganography, Mekhatronika, Avtomatizatsiya, Upravlenie, 2016, vol. 17, no. 6, pp. 498-504.

DOI: 10.17587/mau.17.498-504

\section{References}

1. Rathkeen L. S. Sravnitel'nyi analiz bespilotnykh letatel'nykh apparatov samoletnogo tipa, primenyaemykh dlya resheniya zadach avtomatizirovannogo promyshlennogo i ekologicheskogo monitoringa sostoyaniya ob"ektov (The comparable Analyses of Aircraft Unmanned Flying Systems for Automatic Industrial and Ecological Monitoring of Object State), Mekhatronika, Avtomatizatsiya, Upravlenie, 2012, no. 7 , pp. $58-62$.

2. Web-site of Holding "Helicopters of Russia", available at: www.mi-helicopter.ru.

3. Ratnikova N. A. Teoreticheskye osnovy, apparatnye sredstva $i$ programmno-matematicheskoye obespechenie informatsionnoy systemy monitoringa I kontrolya po sostoyaniyu vozdushnykh sudov (Theoretical basis, device meanings and software-mathematical supporting of information systems for monitoring and checking of aircraft systems), Dissertation for scientific degree of Doctor of Technical Sciences, Moscow, 2005 (in Russian).
4. Web-site of "Schiebel", available at: www schiebel.net.

5. Web-site of ZALA AERO, available at: www.zala.aero.

6. The history of Raytheon, available at: http://www.ravtheon.com/ourcompany/history/.

7. Voennye izvestya (Military news), PC WEEK/RE, 2016, no. 1-5. p. 6 (in Russian).

8. Web-site of IRKUT, available at: www.irkut.com.

9. Web-site of RosAeroSystems, available at: www.rosaerosystems.ru.

10. The history of iRobot, available at: http://www.irobot.com/ About-iRobot/Company-Information/History.aspx.

11. Web-site of Bauman State University, available at wvvw.bmstu.ru.

12. Web-site of State National Center of Russian Federation "Central scientific-researching and experience-construction institute of robot-technique and technical cybernetics", available at: www.rtc.ru.

13. Shilov A. E. Kompleksny podkhod $\kappa$ sozdanyu integrirovannykh globalnykh navigatsionnykh sputnikovykh system (Complex approach for creation of integrative global navigation satellite systems), Dissertation for scientific degree of Candidate of Technical Sciences, Moscow, 2007 (in Russian)

14. Mirzoyan L. A. Neirosetevaya systerna planirovania poleta gruppy bespilotnikh letetel 'nykh apparartov (Neuronet system for planning of fly of group of unmanned aircrafts), Dissertation for scientific degree of Candidate of Technical Sciences, Moscow, 2007 (in Russian).

15. Gaiduk A. R. Control by Group of Unmanned Aerial Vehicles with Restriction on Control Actions and State Variables, Mekhatronika, Avtomatizatsiya, Upravlenie, 2012, vol. 14, no. 7, pp. 52-57.

16. Rathkeen L. S. Patent for invention no. 2322693.

\section{Издательство «НОВЫЕ ТЕХНОЛОГИИ»}

107076, Москва, Стромынский пер., 4

Телефон редакции журнала: (499) 269-5397, тел./факс: (499) 269-5510

Технический редактор Е. В. Конова. Корректор Е. В. Комиссарова.

Сдано в набор 28.04.2016. Подписано в печать 15.06.2016. Формат $60 \times 88$ 1/8. Бумага офсетная.

Усл. печ. л. 8,86. Заказ МН716. Цена договорная.

Журнал зарегистрирован в Комитете Российской Федерации по делам печати, телерадиовещания и средств массовых коммуникаций

Свидетельство о регистрации ПИ № 77-11648 от 21.01.02

Учредитель: Издательство "Новые технологии"

Оригинал-макет ООО "Адвансед солюшнз". Отпечатано в ООО "Адвансед солюшнз".

119071 , г. Москва, Ленинский пр-т, д. 19, стр. 1 